\title{
Relações de parentesco como alavancagem para conversão de capital político
}

\author{
José Lázaro Ferreira Barros Junior 1
}

\begin{abstract}
RESUMO: Por meio de uma analogia com o mercado financeiro, busca-se corrigir uma inconsistência no modelo de análise proposto pelo autor, em 2011, na dissertação "Desempenho eleitoral nas eleições proporcionais de 2008 em Curitiba", sobre a instrumentalização das relações pessoais no processo de conquista do voto. Na época, a classificação elaborada a partir de entrevistas qualitativas com candidatos eleitos para a Câmara de Vereadores colocou lado a lado, com diferentes qualidades de capital social (de ligação, de ponte, de conexão, solidariedade comprometida e imperativo moral), as relações de parentesco e o protagonismo nos meios de comunicação social. Entendia-se que esses sete tipos de relações pessoais podiam ser convertidas em capital político. Contudo, feita a reanálise do trabalho de campo, percebeu-se que os dois últimos, em especial as relações de parentesco, não concorrem com os outros tipos de capital social - pelo contrário, são evocadas para catalisar a conversão daqueles laços sociais em desempenho eleitoral. No mercado financeiro, um procedimento semelhante é chamado de alavancagem, quando uma pessoa toma empréstimo para realizar uma segunda operação de capitais. Neste artigo é sugerido que a alavancagem baseada nas relações de parentesco influencia a política, notadamente marcada por assimetrias de informação, como uma operação em que o nome da família, por exemplo, é oferecido como garantia da transação - no caso, da representação política.
\end{abstract}

Palavras-chave: Parentesco. Família. Eleições. Capital social.

\section{Kinship relations as leverage for political capital conversion}

\begin{abstract}
Through an analogy with the financial market, an attempt is made to correct an inconsistency in the analysis model proposed by the author, in 2011, in the dissertation "Electoral performance in the 2008 proportional elections in Curitiba", on the instrumentalization of personal relations in the process of Achievement of the vote. At the time, the classification elaborated from qualitative interviews with candidates elected to the City Council placed side by side, with different qualities of social capital (of connection, bridge, connection, compromised solidarity and moral imperative), relations of Kinship and protagonism in the media. It was understood that these seven types of personal relationships could be converted into political capital. However, after the reanalysis of the fieldwork, it was noticed that the last two, especially kinship relations, do not compete with other types of social capital - on the contrary, they are evoked to catalyze the conversion of those social ties into electoral performance. In the financial market, a similar procedure is called leverage, when a person borrows to carry out a second capital operation. In this article it is suggested that leverage based on kinship relations influences politics, notably marked by information asymmetries, as an operation in which the family name, for example, is offered as a guarantee of the transaction - in this case, of political representation.
\end{abstract}

Keywords: Kinship. Family. Elections. Share capital.

- Enviado em 01/05/2017

- Aprovado em 17/05/2017

1 Doutorando em Sociologia na UFPR. Jornalista da Câmara Municipal de Curitiba e do coletivo Livre.jor, de jornalismo de dados públicos. Uma versão preliminar desse texto foi apresentada no VIII Seminário Nacional de Sociologia e Política realizado de 17 a 19 de maio de 2017 na UFPR E-mail: zelazaro@gmail.com 


\section{INTRODUÇÃO}

Se você pertencer a uma família política tradicional, e optar por ingressar ativamente neste campo, para constituir uma carreira, terá mais chances de se sair bem-sucedido que outras pessoas desprovidas dessas relações de parentesco. É o que indicam as evidências acumuladas desde 1994 pelo Núcleo de Estudos Paranaenses (NEP), vinculado ao Programa de Pós-Graduação em Sociologia da UFPR. ${ }^{2}$

São 23 anos de pesquisa dedicados à reconstituição de trajetórias de vida dentro da política regional. Nelas, as relações de parentesco são variável independente para as carreiras políticas, cristalizadas na ocupação de postos de mando na administração pública e no desempenho eleitoral. Em 2011, a dissertação "Desempenho eleitoral nas eleições proporcionais de 2008 em Curitiba" vinculou-se às interpretações do NEP para estudar a composição da legislatura 20092012 da Câmara de Vereadores. ${ }^{3}$

Na pesquisa, buscou-se aprofundar uma abordagem esboçada pelo cientista político Luís Felipe Miguel (2003), que propunha ser a conversão de outros capitais em capital político a explicação para a eleição de deputados federais "novatos" na política - quer dizer, sem experiência anterior com vitória eleitoral.

Naquele momento, Miguel constatou haver regularidades na trajetória política de candidatos eleitos para o Congresso Nacional da 48a a 51aㅡ legislaturas (1986, 1990, 1994 e 1998 respectivamente), cujas trajetórias geralmente iniciavam-se nas Câmaras Municipais, com passagem à Assembleia Legislativa, para depois ocupar postos na Câmara dos Deputados e no Senado Federal. Ele chamou essa carreira política de ortodoxa, fixando-a no diagrama disposto a seguir.

Mas registrou também a ocorrência dos "novatos", que, então em cargos de liderança sindical, obtiveram sucesso nas urnas já na disputa por uma vaga federal. É para essa carreira

\footnotetext{
2 Para uma compreensão mais ampla do trabalho do NEP, consultar as obras do coordenador do núcleo, o cientista social Ricardo Costa de Oliveira (2001, 2004, 2007 e 2012), e o material publicado na revista eletrônica do grupo de pesquisa http://revistas.ufpr.br/nep.

${ }^{3}$ Dissertação defendida pelo autor deste artigo em 23 de março de 2011. Versão completa disponível na Biblioteca Digital da UFPR - http://dspace.c3sl.ufpr.br:8080/dspace/handle/1884/32232. Acesso 13.maio.2017
} 
heterodoxa que o pesquisador propôs o modelo de conversão de outros capitais em capital político - apropriado pela dissertação. Só que em vez de aplicar a hipótese a cargos federais, buscou-se problematizá-la na base do diagrama, cujos pleitos têm mais "novatos", logo mais material de estudo.

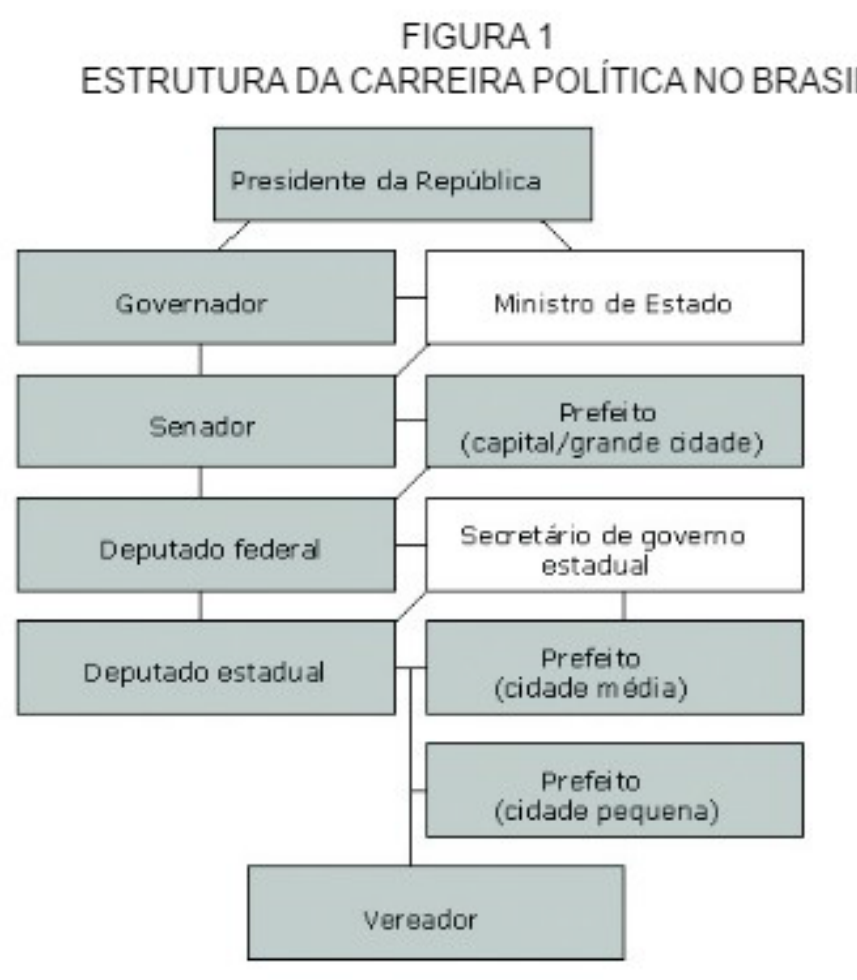

FONTE: Miguel (2003, p. 3)

Apropriar-se do modelo implicou em traduzi-lo para termos mais complexos, ainda que a dissertação estivesse informada pelo mesmo construtivismo estruturalista oriundo da sociologia de Bourdieu, cujos conceitos de campo e de capitais simbólicos, por exemplo, Miguel (2003) utilizou. $\mathrm{Na}$ base do raciocínio está a percepção que o voto é a externalização de uma relação unidirecional de reconhecimento, na qual o eleitor atesta que um determinado candidato está apto a representá-lo politicamente

Para Bourdieu, o político eleito é aquele capaz de inspirar nos outros o sentimento de que ele é competente para a tarefa em questão: ser presidente da República, síndico do prédio, dirigente partidário. ${ }^{4}$ Isso pode ser dar em decorrência da atuação partidária do político ("capital político delegado") ou de capitais pessoais dele, cujo prestígio e notoriedade compensariam

${ }^{4}$ Ver principalmente a parte III do livro “O Poder Simbólico" (Bourdieu, 2000). 
lacunas de atuação institucional ("capital político convertido"). Portanto, diz o modelo, seria possível converter capital cultural, capital econômico e capital social em votos.

\section{PARENTESCO NÃO É (SÓ) CAPITAL SOCIAL}

$\mathrm{Na}$ dissertação, a partir do estudo de Miguel (2003), que constatou a entrada de sindicalistas "novatos" na disputa eleitoral para a Câmara dos Deputados, o desenho de pesquisa concentrou-se no capital social. Buscou-se aflorar os mecanismos de cooperação mobilizados pelos candidatos eleitos, avaliando-se por meio de metodologia qualitativa o acesso diferenciado destes aos recursos disponíveis nas redes sociais, associações civis e sistemas de confiança compartilhada.

A partir de entrevistas semiestruturadas com seis parlamentares, ${ }^{5}$ e da revisão de leitura sobre capital social, elaborou-se uma tipologia. Considerando relações interpessoais formadas por laços sociais fortes e fracos, ${ }^{6}$ as redes sociais foram separadas em três tipos distintos (de ligação, de ponte e de conexão). Duas classificações adicionais, "imperativo moral" e "solidariedade comprometida", foram tomadas de Portes (2000). E, da contribuição brasileira, incluiu-se o papel dos comunicadores sociais e das relações de parentesco. ${ }^{7}$

\footnotetext{
${ }^{5} \mathrm{Na}$ dissertação foram entrevistados os seguintes vereadores eleitos em 2008, então filiados aos partidos indicados: Felipe Braga Côrtes (PSDB), Omar Sabbag Filho (PSDB), Julião Sobota/Julião da Caveira (PSC), Caíque Ferrante (PRP), Pedro Paulo (PT) e Zé Maria (PPS). O questionário utilizado foi experimentado anteriormente, na especialização em sociologia política também cursada no Programa de Pós-Graduação da UFPR, ocasião em que foram ouvidos parlamentares eleitos em 2004, a saber: André Passos (PT), Ângelo Batista (PP), Celso Torquato (PSDB), Elias Vidal (PP), João Cláudio Derosso (PSDB), Osmar Bertoldi (PFL), Serginho do Posto (PSDB) e Tico Kuzma (PPS). As perguntas foram desenvolvidas a partir de questionário utilizado pelo Banco Mundial para medir o capital social em países em desenvolvimento (GROOTAERT; NARAYAN; JONES; WOOLCOCK, 2003).
}

${ }^{6}$ Os laços fortes são aqueles em que os indivíduos despendem mais tempo, intensidade emocional e trocas, como as relações de amizade e parentesco. Já os fracos são aqueles em que o investimento por parte das pessoas é menor ou nulo, como os contatos esporádicos com colegas de trabalho, aos quais só se deseja "bom dia" (MARTELETO e SILVA, 2004, p. 43).

\footnotetext{
${ }^{7}$ Rapidamente (i) "capital social de ligação" é reconhecível em redes sociais horizontais, ocorrendo entre indivíduos que compartilham características sociodemográficas, tais como família, vizinhos, amigos e colegas de trabalho; (ii) as redes sociais constituídas ao redor do "capital social de ponte" são formações entre comunidades distintas, mas com interesses em comum, correspondendo às associações profissionais ou de interesses difusos; (iii) quando uma pessoa se coloca como elo entre dois grupos sociais aos quais pertence, de forma a deslocar recursos de um para o outro, ele está se valendo de "capital social de conexão", típico de formações verticais; (iv) a "solidariedade comprometida" busca agrupar casos de identidade instrumental, como a simpatia por grupos de direitos humanos, de preservação do meio ambiente; (v) por último, "imperativo moral” é quando a identificação se dá pelo acionamento de valores introjetados, levando as pessoas a se relacionarem compulsoriamente - como nas comunidades religiosas.
} 
Entendia-se que esses sete tipos de relações interpessoais podiam ser convertidas em capital político, como demonstra o diagrama a seguir, elaborado com o intuito de facilitar a visualização do modelo de análise proposto. Nele, as letras indicam os pressupostos considerados pela pesquisa e os números a correspondente visualização dos enunciados.

\section{Diagrama 01}

Representação visual da interpretação do desempenho eleitoral a partir da pesquisa realizada em 2011

\section{A - Capital social é uma variável independente para o desempenho eleitoral}

$\begin{array}{lll}\text { 1. } & \mathbf{D E}=\mathbf{C P} & \text { Onde: } \\ \text { 2. } & \text { DE significa "Desempenho Eleitoral" } \\ \text { CP equivale a "Capital Politico" } & \text { CPd é "Capital Politico Delegado" } \\ \text { 3. } & \text { CPC é "Capital Politico Convertido" } \\ & \text { CC é "Capital Cultural" } & \text { CPd }+C P c \\ & \text { CE é "Capital EConômico" } \\ & \text { CS é "Capital Social" }\end{array}$

B - O capital social pode ser decomposto em unidades interpretativas menores

4.

$$
\Sigma \mathrm{CS}=\mathrm{CSlig}+\mathrm{CScon}+\mathrm{CSpon}+\mathrm{IM}+\mathrm{SC}+\mathrm{RP}+\mathrm{MC}
$$

Onde:

CSlig é "Capital Social de Ligação", CScon é "Capital Social de Conexão", CSpon é"Capital Social de Ponte", IM é "Imperativo Moral", SC é "Solidariedade Comprometida", RP são "Relações de Parentesco" e MC significa "Meios de Comunicação".

C - Cada tipo de capital social é uma variável independente parcial para o desempenho eleitoral e deve ser analisada para a compreensão da conquista do voto, dentro do conjunto das hipóteses.

5.

$$
D E=C P d+\left(C C+C E+\sum C S\right)
$$

Contudo, retornando cinco anos depois ao texto finalizado em 2011, percebeu-se na dissertação malformações nesses enunciados. Ao revisar as entrevistas e as notas da pesquisa de campo percebeu-se que (i) as relações de parentesco e o protagonismo nos meios de comunicação exerciam papel diferente do que o assinalado, uma vez que extrapolam a circunscrição do somatório dos capitais sociais; (ii) parentesco e exposição midiática apareciam acoplados a descrições relacionadas a outros capitais; e (iii) parentesco e exposição midiática eram associadas 
ao processo de conversão dos outros capitais em capital político, perdendo importância após o candidato se apropriar desses recursos.

\section{PARENTESCO COMO ALAVANCAGEM}

Apesar de a bolsa imobiliária americana ter estourado em 2008 ${ }^{8}$, repercutindo negativamente no desempenho da economia mundial pelos anos seguintes, só tomei conhecimento das cirucnstâncias ao ler o livro "O Sinal e o Ruído", de Nate Silver (2013), em 2015. Lá, na obra dedicada à discussão dos limites da estatística como "ciência das previsões", ele descreve como o mercado de valores e as agências de avaliação de risco falharam ao não calcular o grau de alavancagem da economia.

Na realidade, o mercado imobiliário consiste numa fatia bem pequena do sistema financeiro. Em 2007, o volume total de vendas de casas nos Estados Unidos somou 1,7 trilhão de dólares - um número modesto se comparado aos 40 trilhões de dólares em ações negociadas a cada ano. Porém, em dissonância com o que estava acontecendo na economia real, Wall Street vinha aumentando, de modo frenético, suas apostas no mercado imobiliário. Também em 2007, o volume total de negócios em títulos lastreados em hipotecas somou cerca de 80 trilhões de dólares. Ou seja, para cada dólar que alguém estava disposto a colocar numa hipoteca, Wall Street estava apostando quase 50 dólares. Temos, agora, todos os ingredientes de uma crise financeira: as apostas dos compradores de imóveis eram multiplicadas por cinquenta. O problema pode ser resumido numa única palavra: alavancagem [grifo nosso]. Se você toma emprestado 20 dólares para apostar que o Redskins vai vencer os Cowboys, está fazendo uma aposta alavancada. Da mesma forma, ocorre alavancagem quando tomamos dinheiro emprestado através de uma hipoteca ou para apostar em títulos lastreados em hipoteca. (SILVER, 2003, p. 41)

O contato com essa expressão do mercado financeiro - a "alavancagem" - serviu como gatilho para operacionalizar uma nova hipótese de pesquisa, no intuito de revisar as malformações nos enunciados sobre as relações de parentesco (i. e. sobre a exposição midiática também, que daqui em diante fica subentendida como opção na metodologia a ser proposta).

A alavancagem substituiu a ideia de que as relações de parentesco talvez atuassem como catalisador da conversão de outros capitais em capital político, acelerando o processo de formação do voto no eleitor. É que a analogia com a química poderia sugerir, erroneamente, que basta adicionar relações de parentesco à composição para obter sucesso eleitoral. Linguisticamente a

\footnotetext{
${ }^{8}$ Ver o capítulo “Um erro de previsão catastrófico", no livro “O Sinal e o Ruído” (SILVER, 2013).
} 
ideia de "catalisador" era deficitária ao não apor à hipótese a possibilidade de insucesso. Este problema é resolvido com a analogia ao mercado financeiro, especialmente quando se pensa que as relações de parentesco são tomadas de empréstimo dos antepassados, para que o candidato aumente suas chances de sucesso dentro do campo político. Contudo, ele compete nesse meio contra os demais operadores, que podem, ou não, dispor também de relações de parentesco. A partir disso, o diagrama com os enunciados foi atualizado, para contemplar a hipótese da alavancagem.

\section{Diagrama 02}

Representação visual da interpretação do desempenho eleitoral atualizada pela alavancagem na conversão de capital político

A - Cada tipo de capital social é uma variável independente parcial para o desempenho eleitoral e deve ser analisada para a compreensão da conquista do voto, dentro do conjunto das hipóteses.

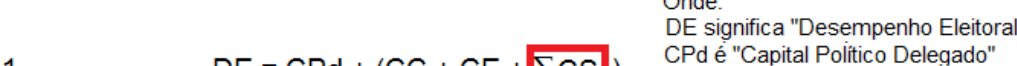

$$
\begin{aligned}
& \text { 1. } \quad \mathrm{DE}=\mathrm{CPd}+(\mathrm{CC}+\mathrm{CE}+\overline{\mathrm{CCS}}) \quad \begin{array}{l}
\mathrm{CPd} \text { é "Capital Politico Delegado" } \\
\mathrm{CC} \text { é }
\end{array} \\
& \text { CE é "Capital Econômico" } \\
& \text { CS é "Capital Social" }
\end{aligned}
$$

B - Diferente do proposto, as relações de parentesco e os meios de comunicação não devem ser tipificados como capital social.

2.

$$
\Sigma C S=C S l i g+C S c o n+C S p o n+I M+S C+C+1
$$

Onde:

CSlig é "Capital Social de Ligação", CScon é "Capital Social de Conexão", CSpon é"Capital Social de Ponte" IM é "Imperativo Moral", SC é "Solidariedade Comprometida", RP são "Relações de Parentesco" e MC significa "Meios de Comunicação".

C - Relações de parentesco constituem variável independente cuja influência extrapola as relações de capital social, afetando o conjunto dos componentes do desempenho eleitoral se usada para alavancar a obtenção de capital político.

D - Carece de pesquisa complementar a hipótese de os meios de comunicação atuarem com o mesmo efeito sobre o capital social, no sentido de alavancarem transferência de confiança.

$$
\sum C S=(C S l i g)+(C S c o n)+(C S p o n)+(I M)+(S C)
$$


Como se percebe no diagrama, as relações de parentesco são tratadas como um expoente, capaz de potencializar capital social já existente. ${ }^{9}$ Se o pai de um candidato a vereador atuou politicamente na mesma base eleitoral agora buscada pelo filho, e o antepassado foi capaz, por exemplo, de trazer benfeitorias para a área, a expectativa presumível dos eleitores é que o descendente repita os feitos de quem o precedeu. A instrumentalização da relação de parentesco aciona essas expectativas, alavancando capital social que será convertido em capital político.

Retornando a Bourdieu, as relações de parentesco atuam aqui como estrutura invisível ${ }^{10}$, externa aos capitais simbólicos, mas que precisa ser pareada a eles para explicar como os políticos João Claudio Derosso, Felipe Braga Côrtes e Omar Sabbag Filho por exemplo, entrevistados para trabalhos anteriores desse pesquisador, conseguiram se posicionar em vantagem no campo político municipal quando se lançaram candidatos à Câmara de Vereadores na primeira vez. Essa competição acirrada, destacada pelo cientista social, é uma das características distintivas do campo político.

\begin{abstract}
O que faz com que a vida política possa ser descrita na lógica da oferta e da procura é a desigual distribuição dos instrumentos de produção de uma representação do mundo social explicitamente formulada: o campo político é o lugar em que se geram, na concorrência entre os agentes que nele se acham envolvidos, produtos políticos, problemas, programas, análises, comentários, conceitos, acontecimentos, entre os quais os cidadãos comuns, reduzidos ao estatuto de "consumidores" devem escolher, com probabilidades de mal-entendido tanto maiores quanto mais afastados estão do lugar da produção. (BOURDIEU, 2000, p. 164)
\end{abstract}

O comum para esses casos seria reconstituir a trajetória de vida desses políticos, posicionando-os como a sequência de uma tradição calcada na presença duradoura da família no campo político em questão. Dir-se-ia que, em decorrência dessa permanência, eles usufruíram de mais recursos que seus rivais, perpetuando-se dentro do campo político pela acumulação desses

\footnotetext{
9 “O capital social é o conjunto de recursos atuais ou potenciais que estão ligados à posse de uma rede durável de relações mais ou menos institucionalizadas de interconhecimento e de inter-reconhecimento ou, em outros termos, à vinculação a um grupo, como conjunto de agentes que não somente são dotados de propriedades comuns (passíveis de serem percebidas pelo observador, pelos outros ou por eles mesmos), mas também são unidos por ligações permanentes e úteis. Essas ligações são irredutíveis às relações objetivas de proximidade física (geográfico) ou no espaço econômico e social porque são fundadas em trocas inseparavalmente materiais e simbólicas cuja instauração e perpetuação supõem o reconhecimento dessa proximidade (...) Os lucros que o pertencimento a um grupo proporciona estão na base da solidariedade que os torna possível” (BOURDIEU, 2007, p.67).

${ }^{10}$ As noções de campo e habitus caminham muito próximas nas teorizações de Bourdieu, que, por mais de uma vez, chamou a ambas de estruturas invisíveis, estruturas essas que seriam, "um pouco, como a força da gravidade, coisas que ninguém vê, mas que é preciso supor para compreender o que se passa" (BOURDIEU, 1996, p. 75). Por aproximação, utilizou-se a mesma epistemologia para supor a influência das relações de parentesco no desempenho eleitoral dos candidatos.
} 
capitais. Esse é o raciocínio frequente na bibliografia. Contudo, a conquista de fazer do pertencimento à genealogia dominante uma evidência sociológica não pode deixar de estimular a metodologia para que, a partir disto, ela desenvolva instrumental para delinear como essas relações de parentesco operam sobre os laços sociais, na composição do desempenho eleitoral. ${ }^{11}$

\title{
3. GÊNESE E FUNCIONAMENTO
}

A ideia da alavancagem é apresentada, neste artigo, como introdução a uma proposta de deslocamento metodológico desdobrada das pesquisas realizadas pelo NEP. Comentando o poder de enunciação dos políticos, que no trecho a seguir Bourdieu chama de porta-vozes, o sociólogo comentará que a representação política deveria ser duplamente encarada pela metodologia: na sua gênese e no seu funcionamento.

\begin{abstract}
O mistério do processo de transubstanciação que faz com que o porta-voz se torne no grupo que exprime só pode ser penetrado por uma análise histórica da gênese e do funcionamento da representação [grifo nosso], pela qual o representante faz o grupo que o faz a ele: o porta-voz dotado de pleno poder de falar e de agir em nome do grupo e, em primeiro lugar, sobre o grupo pela magia da palavra da ordem, é o substituto do grupo que somente por esta procuração existe; personificação de uma pessoa fictícia, de uma ficção social, ele faz sair do estado de indivíduos separados os que ele pretende representar, permitindo-lhes agir e falar, através dele, como um só homem. Em contrapartida, ele recebe o direito de se assumir pelo grupo, de falar e de agir como se fosse o grupo feito homem: “I'Etat c'est moi", "o Sindicato pensa que...". (BOURDIEU, 2000, p. 159).
\end{abstract}

\footnotetext{
${ }^{11}$ Questionamento semelhante é apresentado por Nan Lin, referindo-se à emergência da noção de capital social na sociologia e na economia. A seguir, reproduz-se trecho da obra, em tradução livre: "Um dos esquemas explicativos de maior alcance na sociologia e economia contemporâneas gira em torno do conceito de capital (...) Quando recursos estão investidos e orientados para a obtenção de lucro - como uma meta a ser alcançada - o conceito de capital tratase de recursos. Dessa forma, capital é um recurso duplamente processado. Em um primeiro momento, esses recursos são obtidos ou alterados a servir como investimento; numa segunda etapa, os recursos levantados ou modificados são oferecidos no mercado para a obtenção de lucro. Por um lado, capital é a conseqüência de um processo produtivo (que gerou ou adicionou valor ao recurso original); por outro, ele é a origem do processo produtivo (o recurso é trocado com a intenção de gerar lucro). E esses recursos são processos por envolverem duplamente tempo e esforço. Há duas décadas, a noção de capital social surgiu em suas variadas formas e contextualizações como um dos tipos mais proeminentes de capital. Embora muita agitação tenha sido gerada, com visões, perspectivas e expectativas diferentes, uma das questões levantadas é séria: é uma moda passageira, ou essa abordagem possui qualidades para abrir um novo campo de explorações intelectuais?" (LIN, 2001, p. 03)
} 
O Núcleo de Estudos do Paraná já realiza o mapeamento sistemático das famílias associadas ao campo político brasileiro, em especial daquelas radicadas no Paraná. Dedica-se à gênese histórica desses grupos sociais e se encarrega de localizar, na sociologia política, as reproduções sociais provocadas pela presença de famílias na disputa pelo poder. ${ }^{12}$

A segunda linha de trabalho seria, portanto, uma tentativa de interpretar o funcionamento deste mecanismo. Sugere-se a adoção da observação participante e da etnografia, em moldes semelhantes aos já estipulados pelo cientista político Fenno Jr. Na dissertação, constava a indicação para essa agenda de trabalho, defendida por Paula (2010), que, na sua análise do tema da conexão eleitoral, ${ }^{13}$ argumenta a importância de uma pesquisa empírica que esmiuçasse a interação político-eleitor, observando-a diretamente durante e após a campanha. No entanto, a referência feita há seis anos, a título de revisão da literatura, deixou de problematizar adequadamente a proposta.

\footnotetext{
12“'As famílias possuem a sua origem social, a sua história, a sua genealogia, os seus sobrenomes, as suas biografias e prosopografias. Na história de cada família encontramos as suas formas de existência material, as suas relações sociais de produção, a relação com as forças produtivas, as suas trajetórias sociais, o tipo de status social, o locus e a posição de classe na estrutura social. Formas de trabalho, propriedades e patrimônios familiares, rendas, valores, culturas e identidades podem ser investigados. $O$ processo de modernização não foi uma ruptura ou descontinuidade, mas uma metamorfose em que o antigo e o arcaico se associam, se misturam e prosseguem dialeticamente no moderno. 0 levantamento e a análise dos nepotismos a cada eleição, a cada nomeação, a cada indicação, a cada governo tem sido o interesse do grupo". (OLIVEIRA, 2015, p. 4-5)
}

${ }^{13} \mathrm{O}$ termo "conexão eleitoral" refere-se a um tipo determinado de pesquisa, originalmente utilizado pelos cientistas políticos norte-americanos: "Em linhas gerais, pode-se dizer que um dos principais aspectos da transformação observada nas obras de inspiração institucionalista, que ocorre a partir de meados do século XX, diz respeito à substituição como foco de atenção e pesquisa: dos pioneiros exames comparativos das macroestruturas formais e legais passa-se, posteriormente, para as análises de comportamentos de atores políticos individuais ou coletivos, no contexto de interações determinadas e específicas. A partir do final da década de 1960 e do início da década de 1970 nos Estados Unidos da América, trabalhos inovadores, tendo como foco de atenção específica o Congresso americano, como foram os apresentados em 1965 por Fenno Jr. (1971) e Mayhew (1974), por exemplo, abriram o espaço para uma nova e ampla agenda de pesquisa sobre o comportamento dos atores políticos e sobre o contexto institucional que circunscreve as suas escolhas. Nesses estudos acerca do comportamento dos atores políticos e, também, sobre a conformação das instituições legislativas que os circunscrevem podem ser identificados três aspectos centrais que se destacam e para os quais convergem, também no Brasil, as principais discussões teóricas no final do século XX: a) a "conexão eleitoral", em que se associa a motivação para a ação política ao sucesso nas eleições e, consequentemente, à continuidade de carreiras dos atores políticos; b) a relação personalizada dos atores políticos com suas bases eleitorais e as consequências da personificação do voto sobre o sistema político-partidário; c) o papel das estruturas de poder internas no Congresso na definição e no controle de agendas e, portanto, na produção legislativa. A relação entre o interesse egoísta dos indivíduos e seu comportamento que, como já se disse, constitui um dos axiomas da teoria da escolha pública, permanece também subjacente em várias das construções teóricas e pesquisas empíricas mais recentes. Esse é o caso, por exemplo, dos estudos sobre a conexão eleitoral, desenvolvidos a partir de meados dos anos 1970 nos Estados Unidos, principalmente" (FLEURY, 2009, p. 33-34). 
Na compreensão do relacionamento entre representantes e bases eleitorais, uma tentativa bemsucedida na adoção de uma perspectiva empírica e metodológica mais plural foi realizada por Fenno Jr.(1990) no contexto dos EUA. Em "Watching Politicians - essays on participant observation" o autor apresenta cinco artigos escritos ao longo de vários anos de pesquisa acadêmica, inclusive dois textos de cunho metodológico, que permitem vislumbrar procedimentos - como a etnografia e a observação participante, por exemplo - bastante viáveis na análise do comportamento parlamentar, porém raramente utilizados nos estudos da Ciência Política brasileira. (...) Destacou-se neste texto que os estudos da Ciência Política interessados na problemática utilizaram enquanto método de pesquisa a aplicação de surveys ou entrevistas em profundidade. O problema desses dois procedimentos é que as conclusões limitam-se à percepção do entrevistado, por isso, a proposta aqui é utilizar o método etnográfico. Assim como Fenno Jr. (1990) acredita-se na pertinência na análise das atividades dos parlamentares em seus próprios locais de votação durante o exercício do mandato. Esse procedimento elucidaria conhecer uma dimensão da conexão eleitoral ainda pouco explorada na Ciência Política nacional, afinal, de que maneira os deputados federais brasileiros organizam seu próprio mandato? Como são as suas redes nos municípios? (PAULA, 2010, p.129-130)

Acredita-se ser possível, sem descartar as entrevistas em profundidade com os candidatos como contato inicial, conjugar à técnica (i) a análise de discurso sobre as peças de comunicação pessoal e (ii) a observação participante. Se a alavancagem, como se pode presumir no campo das hipóteses, opera decisões íntimas ao eleitor, é preciso que a pessoa seja exposta às estratégias do político para que a conversão de capitais ocorra.

Portanto, mais do que analisar como a relação com a base eleitoral se processa, pede-se que futuras pesquisas nesta área direcionem esforços para o registro de como as relações de parentesco se manifestam na interação entre político e cidadão - avançando na interpretação desta variável independente para o desempenho eleitoral.

Paula (2010) está correta em apontar a falta de pesquisas etnográficas em política no Brasil, especialmente no campo da Ciência Política, mas é preciso ressalvar a publicação, na virada dos anos 1990 para os 2000, da coleção "Antropologia da Política", organizada pelo Núcleo de Antropologia da Política (NuAP), da UFRJ. ${ }^{14}$ No conjunto de sete livros, estão, por exemplo, a obra "Em nome das bases: política, favor e dependência pessoal”, de Marcos Otávio Bezerra,15 e "Em nome de quem? Recursos sociais no recrutamento de elites políticas", de Odaci Luiz Coradini.

\footnotetext{
${ }^{14}$ Para um panorama da Coleção Antropologia da Política, ver a resenha de Steil (2000).

${ }^{15}$ Nela o pesquisador fará um relato detalhado de como os parlamentares do Congresso Nacional comportam-se no meio de uma equação cujas variáveis são de duas naturezas diferentes, apesar de complementares: a dificuldade de manter a coesão do seu reduto eleitoral, mediante a negociação com lideranças regionais e políticos que ocupam cargos nos municípios e administrações estaduais; e os mecanismos legislativos para a obtenção das obras, políticas públicas e recursos necessários para corresponder às expectativas dos apoiadores e financiadores de campanha. Na parte final do livro, ele dedica-se à análise da corrupção.
} 
Nesta, Coradini (2001) busca correlações entre a atividade profissional e o desempenho eleitoral. Observando o pleito de 1998 para a Assembleia Legislativa do Rio Grande do Sul, ele analisa como a participação em sindicatos, organizações empresariais e de produtores rurais, igrejas, grupos de filantropia e a ocupação de cargos públicos podem ter influenciado o desempenho dos candidatos nas urnas.

Esse trabalho, cuja proposta é bastante semelhante à da dissertação, passou despercebido na época da minha pesquisa, apesar de a produção de Bezerra (1999) constar na bibliografia utilizada, indicando contato com a proposta do NuAP. Curioso, também, se for considerada a troca de e-mail com Coradini, sobre outro artigo dele, de 2010, sobre a diferença do conceito "capital social" nas obras de Bourdieu e Coleman. Talvez a explicação esteja nas poucas referências explícitas ao marco teórico trabalhado, ainda que Coradini cite Bourdieu 10 vezes no livro, e que as expressões "capital político" (8), "capital cultural" (3), "capital social” (2) e "campo político" (1) ocorram na obra.

\section{INVISIBILIZAÇÃO DO PARENTESCO}

Se for considerada outra produção de Coradini, em 1997, sobre a "elite profissional" da medicina no Brasil, e suas bases nas "grandes famílias", a obra publicada por ele na coleção Antropologia da Política ganha outra dimensão. No artigo, ${ }^{16}$ o pertencimento a famílias é tomado como variável explicativa da formação da elite médica, associando seu potencial de reprodução social à educação formal. Ele dá centralidade a essa abordagem, numa empreitada sociológica que, mesmo presente no livro, acaba colocada em segundo plano ante as características profissionais.

Na obra "Em nome de quem?", de Coradini (2001), a palavra "parentesco" aparece 5 vezes. "Família", 89 vezes, sendo majoritariamente usada para designar a origem social dos candidatos à Assembleia Legislativa do Rio Grande do Sul. Se forem consideradas as ocorrências das expressões “avô" e "avó" (21), "neta" (2), “neto" (6), “mãe” (10), "pai" (107), "filho" (84) e "filha" (9), por exemplo, é possível projetar que, há mais referências a essa categoria analítica que páginas (189)

\footnotetext{
${ }^{16}$ Coradini diz, já na introdução do trabalho, que ele é inspirado pela cientista social Monique de Saint Martin, outra referência comumente citada na produção científica do NEP, ao lado deste trabalho do pesquisador gaúcho. Ela inclui a análise das famílias em seus estudos sobre mobilidade social (1995), sobre trajetórias de vida (LABACHE; SAINT MARTIN, 2008) e sobre as elites na França (2008).
} 
no conjunto da obra. O que explicaria, então, a ausência de uma problematização densa do funcionamento das relações de parentesco no desempenho eleitoral? Uma das colocações frequentes do NEP é a invisibilização das relações de parentesco como categoria analítica das relações de poder. Na sequência, tomamos trechos da obra do pesquisador gaúcho, em que algumas das ocorrências aparecem:

Para um último desses candidatos, sua principal base de recursos eleitorais são as organizações religiosas, por se tratar de um líder católico, além da herança política da família de origem, visto ser filho de um antigo deputado. (CORADINI, 2001, p. 96-97)

Embora ante o esquema de classificação da Justiça Eleitoral se defina como agrônomo, trata-se de um filho de um político da região, grande produtor rural e empresário. Mas, apesar dessa condição de empresário, sua apresentação como candidato está centrada em seu currículo escolar e profissional e na "expressiva trajetória política", além de qualificações como "experiente" e "capaz". (CORADINI, 2001, p. 103)

Assim, no período eleitoral, foi publicado um livro de autoria do candidato sobre a "história da imigração" ("Pioneiros, Aventureiros, Guerreiros e seus Herdeiros"), no qual essa "história" do respectivo grupo familiar se confunde com a da imigração alemã para o estado e com a da própria região. (CORADINI, 2001, p. 104-105)

Natural de um pequeno município de uma região de colonização através da imigração, ele próprio descendente de imigrantes poloneses, mas herdeiro de um grupo familiar economicamente bemsucedido, a vinculação com a política é anterior à sua geração, sendo que o pai foi vereador (pelo antigo PTB, tendo sido cassado em 1964) do município de origem, onde um irmão tinha sido prefeito em 1998 (Herval Grande). Conforme sua própria definição, é proveniente de uma "família tradicional no comércio na região, e isso fez com que a gente se destacasse na região" e devido às condições socioeconômicas da família, os cargos políticos são vistos como "passageiros" (entrevista). (CORADINI, 2001, p. 110-111)

Mas essa liderança política não decorre tanto de sua militância em alguma organização de defesa dos produtores rurais, mas principalmente, por se tratar de um herdeiro de um grupo familiar dominante, muito ativo na política local. Filho de um comerciante e de uma fazendeira na região da grande propriedade agrícola (São Borja), conforme seu depoimento, tanto seu pai como o sogro foram protagonistas principais da política local, no que define como "a terra mais politizada do país" ou "o berço do socialismo" representado pelo antigo PTB. Nessa "terra mais politizada", seu grupo familiar de origem manteve uma posição de disputa com outros politicamente dominantes, na medida em que seu pai, como presidente e líder do então PL (Partido Libertador), se opunha aos líderes do antigo PTB e PSD ou, mais especificamente, Getúlio Vargas e João Goulart. Foi por essa via, como filho do líder local de um partido que se inseriu na política partidária, que lhe deu "origem política", participando da "ala moça do Partido Libertador" e assim, "ajudava ele e ia ficando conhecido"(entrevista). (CORADINI, 2001, p. 113-114)

Colocações como "herança política", "filho de político da região", "história do grupo familiar se confunde com a da imigração na região", "irmão de prefeito" e "herdeiro de um grupo familiar dominante" são utilizadas sem problematização. Se ao tratar das classes profissionais há um esforço de interpretação, ligando a atuação aos recursos simbólicos depositados nessas relações 
sociais, conversíveis em votos, isto não acontece ao abordar as relações de parentesco - que, "naturalizadas", alheias ao processo de disputa de poder, são enunciadas como acontecimentos importantes nas trajetórias de vida dos candidatos estudados, mas terminam invisibilizadas, à sombra da "relevância" discursiva.

\section{CONSIDERAÇÕES FINAIS}

Rapidamente foi apresentado o modelo de análise que embasou a dissertação "Desempenho eleitoral nas eleições proporcionais de 2008 em Curitiba", cujo foco era o adensamento do debate acerca da conversão de capital social em capital político. Depois, foram apontadas as malformações, dentro daqueles enunciados propostos, das interpretações acerca do papel das relações de parentesco na obtenção de capital político. Como alternativa, para superar as deficiências, propôs-se a problematização do pertencimento a famílias políticas como alavancagem de capitais simbólicos.

A hipótese da alavancagem serviria para sair dos estudos de "gênese" para passar aos do "funcionamento" - uma clivagem metodológica inspirada em colocação de Bourdieu sobre como deveriam ser os estudos da representação política. Indicou-se, para tal, uma aproximação da etnografia e da observação participante, recuperando agenda de pesquisa proposta por Paula (2010).

A título de complexificação, num exercício ligeiro sobre a obra "Em nome de quem?" (CORADINI, 2001), mostrou-se como não é a técnica etnográfica que superará sozinha as lacunas nos estudos sobre como "funcionam" as relações de parentesco - mas a necessidade de o pesquisador estar suficientemente equipado para problematizar a questão. Sugere-se, portanto, a combinação da etnografia com a hipótese da alavancagem, devidamente informada pela pesquisa anterior sobre capital social e desempenho eleitoral, como ponto de partida para novas pesquisas. 


\section{REFERÊNCIAS}

BEZERRA, M. O. Em nome das bases - política, favor e dependência pessoal. Rio de Janeiro: Relume Dumará: Núcleo de Antropologia da Política, 1999. 275 págs.

BOURDIEU, Pierre. O poder simbólico. 3.ed. Rio de Janeiro: Bertrand Brasil, 2000. 311 págs.

. O capital social - notas provisórias. In Escritos de Educação. Petrópolis: Vozes, 2007. p. 65-69.

CORADINI, Odaci Luiz. Grandes famílias e "elite profissional" na medicina do Brasil. História, Ciências, Saúde - Manguinhos, n. 3, nov. 1996 - fev. 1997, p. 425-466.

- The divergences between Bourdieu's and Coleman's notion of social capital and their epistemological limits. Social Science Information, v. 49, n. 4, 2010, p. 563-583.

. Em nome de quem? Recursos sociais no recrutamento de elites políticas. Rio de Janeiro: Relume Dumará, 2001. 198 págs. Disponível em: <http://nuap.etc.br/content/uploads/2013/06/em_nome_de_quem.pdf>. Acesso em: 20 abr. 2017.

FLEURY, S. J. F. Redes de proteção: incentivos, escolhas e comportamentos na política brasileira. Belo Horizonte, 2009. 219 f. Tese - Departamento de Ciência Política da Faculdade de Filosofia e Ciências Humanas da Universidade Federal de Minas Gerais.

GROOTAERT, Christiaan; NARAYAN, Deepa; JONES, Veronica; WOOLCOCK, Michael. Questionário Integrado para Medir Capital Social. Banco Mundial. jun. 2003. 73 págs.

LABACHE, Lucette; SAINT MARTIN, Monique de. Fronteiras, trajetórias e experiências de ruputras. Educação e Sociedade, Campinas, v. 29, n. 103, mai./ago. 2008, p. 333-354.

LIN, Nan. Social Capital: a theory of social structure and action. Cambridge University Press: Cambridge, 2011. 278 págs.

MARTELETO, Regina Maria; SILVA, Antônio Braz de Oliveira e. Redes e capital social: o enfoque da informação para o desenvolvimento local. Ciência da Informação, Brasília, v. 33, n. 3, p. 4149, set./dez. 2004.

OLIVEIRA, Ricardo Costa de. O silêncio dos vencedores. Genealogia, classe dominante e Estado no Paraná. Curitiba: Moinho do Verbo, 2001. 447 págs.

(Org.) A construção do Paraná moderno. Políticos e política no governo do Paraná de 1930 a 1980. Curitiba: SETI, 2004. 420 págs. 
. Famílias, poder e riqueza: redes políticas no Paraná em 2007. Sociologias, Porto Alegre, n.18, jul/dez. 2007.

Na Teia do Nepotismo. Sociologia Política das Relações de Parentesco e Poder

Político no Brasil. 1. ed. Curitiba: Insight, 2012. 272 págs.

. Um programa de pesquisas sobre o Paraná. In

e Parentesco no Paraná. Nova Letra: Blumenau, 2015. 386 págs.

PAULA, Carolina de. Para diversificar o estudo da conexão eleitoral no Brasil: uma agenda de pesquisa. Revista Eletrônica de Ciência Política, Curitiba, v. 1, n. 1, set. 2010, p.118- 133. Disponível em http://ojs.c3sl.ufpr.br/ojs2/index.php/politica/article/view/18537/12087. Acesso em 20 de abril de 2017.

PORTES, Alejandro. Capital social: origens e aplicações na sociologia contemporânea. Sociologia: problemas e práticas, n. 33, 2000, p. 133-158.

SAINT MARTIN, Monique de. Reconversões e reestruturações das elites: o caso da aristocracia em França. Análise Social, Lisboa, v. 30, n. 134, 1995, p. 1023-1039.

- Da reprodução às recomposições das elites: as elites administrativas, econômicas e políticas na França. Tomo

SILVER, Nate. O Sinal e o Ruído: por que tantas previsões falham e outras não. Rio de Janeiro: Intrínseca, 2013. 544 págs.

STEIL, Carlos Alberto. Resenha da Coleção Antropologia da Política. Horizontes Antropológicos, Porto Alegre, n. 14, nov. 2000, p. 303-306. 